\title{
Capacidade combinatória e heterose de linhagens de pepino do grupo japonês para caracteres de produção
}

\author{
Juliana G de Lalla ${ }^{1}$; Valdemir Antonio Laura²; Santino Seabra Júnior ${ }^{3}$; Antonio Ismael Inácio Cardoso ${ }^{1}$ \\ ${ }^{1}$ UNESP- FCA, Dep ${ }^{\text {to }}$ Produção Vegetal, C. Postal 237, 18610-307 Botucatu-SP; ${ }^{2}$ Embrapa Gado de Corte, C. Postal 154, 79002-970 \\ Campo Grande-MS; ${ }^{3}$ UNEMAT, Cáçeres-MT; jugadum@hotmail.com; valdemir@cnpgc.embrapa.br; santinoseabra@hotmail.com; \\ ismaeldh@fca.unesp.br
}

\section{RESUMO}

O objetivo do trabalho foi estimar o efeito da capacidade geral (CGC) e específica (CEC) de combinação e a heterose de linhagens e populações de pepino japonês, empregando-se um topcross. Foram obtidos 16 híbridos experimentais a partir de duas populações testadoras (geração $\mathrm{F}_{2}$ de Yoshinari, $\mathrm{T}_{\mathrm{Y}}$ e de Natsusuzumi, $\mathrm{T}_{\mathrm{N}}$ ) e oito linhagens $\mathrm{S}_{5}$ obtidas a partir do híbrido comercial Hokuho. Também foi avaliado o híbrido $F_{1}$ Hokuho, totalizando 27 tratamentos. O delineamento experimental utilizado foi em blocos casualizados, com quatro repetições e cada parcela foi constituída de quatro plantas. Foram avaliadas as massas totais e comerciais, número de frutos total e comercial, porcentagem de frutos comerciais e massa média de frutos comerciais. A população de Yoshinari $\left(\mathrm{T}_{\mathrm{Y}}\right)$ apresentou, em média, melhor capacidade de se combinar com as linhagens de Hokuho. A linhagem $\mathrm{L}_{7}$ apresentou os maiores valores positivos da estimativa da CGC para a maioria das características avaliadas. Os híbridos $\mathrm{H}_{1 \mathrm{Y}}$ e $\mathrm{H}_{1 \mathrm{~N}}$, que apresentavam a linhagem $\mathrm{L}_{1}$ como parental, foram os que apresentaram maiores valores para a estimativa da CEC com as populações testadoras para a maioria das características avaliadas, enquanto os que tinham a linhagem $\mathrm{L}_{5}$ como parental $\left(\mathrm{H}_{5 \mathrm{Y}}\right.$ e $\mathrm{H}_{5 \mathrm{~N}}$ ) apresentaram os menores valores. A população $\mathrm{F}_{2}$ proveniente do híbrido Yoshinari apresentou, em geral, maior potencial de originar linhagens superiores para cruzamentos com linhagens de Hokuho, a fim de se obter híbridos com maior potencial produtivo. A heterose foi positiva para a grande maioria das características avaliadas.

\begin{abstract}
Combining ability and heterosis of lines from Japanese cucumber type for yield

The objective of this work was to estimate general (GCA) and specific combining ability (SCA) and heterosis of lines and populations of Japanese cucumber using a topcross. We obtained 16 experimental hybrids crossing two test populations (Yoshinari, $\mathrm{T}_{\mathrm{Y}}$, and Natsusuzumi, $\mathrm{T}_{\mathrm{N}}, \mathrm{F}_{2}$ population) and eight $\mathrm{S}_{5}$ lines obtained from Hokuho commercial hybrid. The Hokuho hybrid $\mathrm{F}_{1}$ was also evaluated, totalizing 27 treatments. The experimental design used was randomized block, with four replicates and four plants per plot. Weight of total and commercial fruits, total number of fruits, number of commercial fruits, percentage of commercial fruits and average weight of commercial fruits were evaluated. Yoshinari population $\left(\mathrm{T}_{\mathrm{Y}}\right)$ presented, on average, better combining ability with lines of Hokuho. Line $\mathrm{L}_{7}$ presented the highest positive values of GCA for most of evaluated characteristics. Hybrids $\mathrm{H}_{1 \mathrm{Y}}$ and $\mathrm{H}_{1 \mathrm{~N}}$, with line $\mathrm{L}_{1}$ as one parental, showed higher values for SCA with the test populations for most of evaluated characteristics, while the hybrids with line $\mathrm{L}_{5}\left(\mathrm{H}_{5 \mathrm{Y}}\right.$ and $\mathrm{H}_{5 \mathrm{~N}}$ ) showed the smallest values. Population Yoshinari $\mathrm{F}_{2}$ showed greater potential to obtain lines for crossings with lines of Hokuho, in order to obtain hybrid with high yielding potential. Heterosis was positive for most evaluated characteristics.
\end{abstract}

Keywords: Cucumis sativus L., diallel, gene effects, plant breeding.
Palavras-chave: Cucumis sativus L., dialelo, efeito gênico, melhoramento genético vegetal.
(Recebido para publicação em 16 de dezembro de 2008; aceito em 31 de agosto de 2010) (Received on December 16, 2008; accepted on August 31, 2010) essas condições de cultivo, há maior controle ambiental, possibilitando a utilização de cultivares com maior potencial produtivo, destacando-se os híbridos $\mathrm{F}_{1}$ de pepino tipo japonês, que se caracterizam por apresentar frutos tipicamente afilados e alongados, de coloração verde escura. Atualmente, existe um grande número de híbridos no mercado, podendo destacar Tsuyataro, Taisho, Yoshinari e Natsuhikari.

$\mathrm{O}$ uso de sementes híbridas na produção comercial de hortaliças é hoje prática comum nos países desenvolvidos e em desenvolvimento. A utilização de híbridos $\mathrm{F}_{1}$ é motivada pelas vantagens oferecidas aos produtores e consumidores, destacando-se o aumento da produtividade, precocidade, maior uniformidade, melhor padronização e qualidade dos frutos, melhor conservação pós-colheita e estabilidade de comportamento sob condições ambientais variáveis (Koch, 1995; Maluf, 2001).

Embora alógama, o pepino geralmente não apresenta queda de vigor em função da endogamia, porém apresenta destacada heterose. A superioridade de híbridos $\mathrm{F}_{1}$ em pepino foi constatada há mais de nove décadas por Hayes \& 
Jones em 1916, citados por Filgueira et al. (1986), porém o primeiro híbrido comercial de pepino, denominado Burpee Hybrid, introduzido pela "Burpee Seed Company", só foi explorado comercialmente em 1945 (Robinson \& Decker-Walters, 1999). Segundo Maluf (2001), a utilização de linhagens ginóicas de pepino, principalmente a partir da década de 1970, possibilitou a produção em escala comercial de sementes $\mathrm{F}_{1}$.

Do ponto de vista do produtor, o efeito principal esperado da heterose é o aumento da produtividade. Entretanto, conforme sugere Maluf (2001), um grande número de outros caracteres agronômicos economicamente importantes também podem ser melhorados aproveitando-se da existência de heterose. Hutchins (1938) observou efeitos heteróticos para produtividade, número de frutos por planta e também para produção precoce. Ghaderi \& Lower (1978) relataram que os híbridos foram mais produtivos do que os parentais e apresentaram maior estabilidade fenotípica. Delaney \& Lower (1987) observaram heterose para produção, número de ramificações e comprimento de entrenó.

Lower et al. (1982) observaram heterose relativa ao parental superior, tanto para produtividade quanto para comprimento da rama principal. Giordano et al. (1982) encontraram valores de heterose relativa ao parental superior em vários híbridos de pepino de mesa para caracteres relacionados à produção. Heterose positiva foi relatada em um dialelo entre quatro linhagens de pepino por Li et al. (1995) para produção total, produção precoce, número de frutos, massa média de frutos e área foliar e heterose negativa para comprimento de haste. Cardoso (2006), avaliando um dialelo entre linhagens de pepino tipo 'Caipira', observou heterose para produção de frutos em torno de 50\%. Já para pepino japonês a média das heteroses foi menor que 25\% (Cardoso, 2007).

Os programas de melhoramento de cucurbitáceas, visando à obtenção de híbridos $\mathrm{F}_{1}$, utilizam como estratégias o desenvolvimento de linhagens obtidas da autofecundação sucessiva de plantas superiores ou ainda linhagens obtidas de populações segregantes derivadas de híbridos comerciais, com posterior recombinação ou não das linhagens selecionadas (Koch, 1995). Na seleção, o potencial de cada uma dessas linhagens pode ser avaliado por meio de sua capacidade geral e específica de combinação para os diferentes caracteres de interesse agronômico.

Os híbridos de pepino tipo japonês utilizados comercialmente pelos produtores não foram desenvolvidos nas condições edafoclimáticas do Brasil. Desse modo, programas de melhoramento genético devem começar utilizando genótipos comerciais importados, havendo assim a necessidade de obtenção de cultivares nacionais, se possível, mais tolerantes e adaptadas a condições de cultivo no Brasil.

Para a obtenção de híbridos uniformes, uma alternativa é a seleção de linhagens a partir de populações com características desejáveis e a análise da capacidade de combinação dessas. Deste modo, o emprego da análise da capacidade combinatória é utilizado com a finalidade de auxiliar a seleção de combinações híbridas de interesse para o melhoramento de plantas.

Davis (1927) e Jenkins \& Brunson (1932) introduziram o uso do esquema "topcross" para a avaliação do valor genético de linhagens (capacidade de combinação) em cruzamentos, o qual pode ser comparado a um dialelo parcial, ou com mais propriedade, com um delineamento genético fatorial. Segundo este esquema, todas as linhagens de um determinado conjunto são cruzadas com um mesmo testador e o seu valor genético é determinado com base em contrastes de médias de caracteres quantitativos. O uso do esquema topcross tornou-se um processo padrão nos programas de melhoramento de plantas, especialmente no milho (Miranda Filho \& Gorgulho, 2001).

Neste trabalho o objetivo foi estimar a capacidade geral (CGC) e específica (CEC) de combinação, por meio de um topcross entre linhagens e populações de pepino tipo japonês.

\section{MATERIAL E MÉTODOS}

O experimento foi conduzido em área da UNESP-FCA, Campus de Botucatu, localizada no município de São Manuel-SP. Foi realizado de março a maio de 2004, sob ambiente protegido em casa-de-vegetação tipo arco, com 7,0 metros de largura e 20,0 metros de comprimento e pé direito de $1,8 \mathrm{~m}$.

Plantas do híbrido Hokuho (Kyowa), com hábito de florescimento monóicopartenocárpico, foram intercruzadas, obtendo-se a geração $\mathrm{F}_{2}$. Posteriormente, a partir de 23 plantas desta população, foram realizadas cinco gerações sucessivas de autofecundação pelo método do Single Seed Descent até a obtenção de 23 linhagens $\mathrm{S}_{5}$, das quais oito, tomadas ao acaso, foram utilizadas neste experimento $\left(\mathrm{L}_{1} \mathrm{a} \mathrm{L}_{8}\right)$.

Plantas dos híbridos Natsusuzumi e Yoshinari, ambas com hábito de florescimento monóico-partenocárpico, foram também intercruzadas separadamente e obtidas as gerações $\mathrm{F}_{2}$ que foram utilizadas como populações testadoras: $\mathrm{T}_{\mathrm{Y}}$ (população $\mathrm{F}_{2}$ de Yoshinari); $\mathrm{T}_{\mathrm{N}}$ (população $F_{2}$ de Natsusuzumi).

Cada uma das oito linhagens do híbrido Hokuho foi cruzada separadamente com as populações de Natsusuzumi (20 plantas) e Yoshinari (20 plantas), obtendo-se os híbridos experimentais, descritos a seguir: $\mathrm{H}_{1 \mathrm{Y}}, \mathrm{H}_{2 \mathrm{Y}}, \mathrm{H}_{3 \mathrm{Y}}, \ldots, \mathrm{H}_{8 \mathrm{Y}}$ : híbridos experimentais provenientes do cruzamento das linhagens do híbrido Hokuho e a população Yoshinari, representada pela letra "Y", usada como genitor masculino; $\mathrm{H}_{1 \mathrm{~N}}, \mathrm{H}_{2 \mathrm{~N}}, \mathrm{H}_{3 \mathrm{~N}}, \ldots, \mathrm{H}_{8 \mathrm{~N}}$ : híbridos experimentais provenientes do cruzamento das linhagens do híbrido Hokuho e a população Natsusuzumi, representada pela letra "N", usada como genitor masculino. Em ambos os casos, o primeiro número corresponde à linhagem utilizada como genitor feminino proveniente de Hokuho.

Foram avaliados 27 tratamentos: os 16 híbridos experimentais (obtidos conforme descrito anteriormente), oito linhagens, as populações $\mathrm{F}_{2}$ de Yoshinari e Natsusuzumi, e o híbrido comercial Hokuho. O delineamento experimental utilizado foi blocos casualizados com quatro repetições. Cada parcela foi constituída por quatro plantas.

A semeadura foi realizada em 15 de março de 2004, em bandejas de poliestireno expandido de 128 células. O trans- 
plante foi realizado quando as plântulas apresentavam duas folhas definitivas. $\mathrm{O}$ espaçamento utilizado foi de $1,0 \mathrm{~m}$ x 0,5 m. Durante a condução da cultura, a área foi mantida livre de plantas daninhas por meio de capinas manuais e a irrigação foi realizada por gotejamento.

A adubação foi realizada após análise química do solo, de acordo com a recomendação feita pelo Boletim 100 do Instituto Agronômico de Campinas (Trani et al., 1997). O controle de pragas e doenças foi realizado de acordo com a necessidade da cultura, através de pulverizações com inseticida Deltametrina e fungicida Fenarimol.

Cada planta foi tutorada individualmente eliminando-se todas as brotações e flores até o $5^{\circ}$ nó da haste principal. Realizou-se também a desbrota das ramas laterais (após o $6^{\circ}$ nó da haste principal), entre a segunda e terceira folhas. Retirou-se o meristema apical da planta quando esta atingiu a altura do arame (cerca de 1,80 m). As colheitas foram efetuadas três vezes por semana, colhendo-se frutos com cerca de $20 \mathrm{~cm}$ de comprimento.

Foram avaliados a massa total de frutos por planta (pesagem, em balança com precisão de $0,1 \mathrm{~g}$, de todos os frutos colhidos na parcela, obtendo-se a média por planta); massa de frutos comerciais por planta (pesagem de todos os frutos classificados como comercial, retos e sem defeitos, produzidos na parcela, obtendo-se a média por planta); número total de frutos por planta (contagem dos frutos produzidos na parcela, obtendo-se a média por planta); número de frutos comerciais por planta (contagem dos frutos considerados comerciais na parcela, obtendo-se a média por planta); porcentagem de frutos comerciais (percentual de frutos considerados comerciais em relação ao total colhido na parcela) e massa média de frutos comerciais (relação entre massa de frutos comerciais e o número destes).

A partir dos valores médios de cada parcela dos tratamentos, efetuou-se a análise de variância para as características avaliadas para os 27 tratamentos. As diferenças entre as médias foram comparadas pelo teste de Scott-Knott $(\mathrm{p} \leq 0,05)$.

As estimativas dos efeitos da capaci- dade geral (CGC) e específica de combinação foram obtidas de acordo com o modelo de Geraldi \& Miranda Filho (1988), onde foram inclusos somente os genitores e os híbridos experimentais. Também foram obtidas as estimativas, em porcentagem, da heterose dos híbridos em relação à média dos genitores.

\section{RESULTADOS E DISCUSSÃO}

Para as características número de frutos comerciais por planta (NFC/ $\mathrm{PL})$, número total de frutos por planta (NFT/PL), massa de frutos comerciais por planta $(\mathrm{MC} / \mathrm{PL})$ e massa total de frutos por planta (MT/PL) não foram observadas diferenças significativas (Tabela 1). De forma geral, a população de 'Yoshinari' foi a que tendeu a apresentar valores médios superiores, produzindo 12,9 frutos por planta com massa média total de 1536,3 gramas, dos quais 12,4 eram comerciais e a massa em torno de 1200 gramas. A linhagem 1 foi a que apresentou os menores valores para NFC/PL, NFT/PL, MC/PL e MT/PL entre as linhagens avaliadas. Comparativamente a outros autores que estudaram pepino japonês em ambiente protegido, os valores obtidos foram inferiores. Cardoso \& Silva (2003), que testaram 19 híbridos comerciais, verificaram que para o cultivo de verão a produção variou de 17,8 a 25,4 frutos/ planta, e no inverno de 16,1 a 26,8 frutos por planta. Já Cardoso (2007) obteve valores variando de 12,2 a 20,0 frutos/ planta; Oviedo et al. (2008) de 14,3 a 21,6 frutos/planta; e Lima (2009) de 13,2 a 27,0 frutos/planta.

Apenas para as características porcentagem de frutos comerciais $(\% \mathrm{FC})$ e massa média de frutos comerciais (MMFCOM) foram observadas diferenças estatísticas significativas entre os tratamentos pelo teste de Scott-Knott (Tabela 1).

A população de Yoshinari $\left(\mathrm{T}_{\mathrm{Y}}\right)$, bem como os híbridos experimentais que o tinham como um de seus genitores $\left(\mathrm{H}_{\mathrm{Y}}\right)$, com exceção de $\mathrm{H}_{3 \mathrm{Y}}$, foram estatisticamente semelhantes ao 'Hokuho' (testemunha) e às linhagens $\mathrm{L}_{1}, \mathrm{~L}_{2}$, $\mathrm{L}_{4}, \mathrm{~L}_{5}$ e $\mathrm{L}_{7}$ e superiores a população de Natsusuzumi $\left(\mathrm{T}_{\mathrm{N}}\right)$ para a característica $\%$ FC. Já a maioria dos híbridos experimentais contendo 'Natsusuzumi' como um de seus genitores $\left(\mathrm{H}_{\text {.N }}\right)$ foram superiores à população de Natsusuzumi, com exceção dos híbridos $\mathrm{H}_{6 \mathrm{~N}}$ e $\mathrm{H}_{8 \mathrm{~N}}$. Observou-se também que, em média, as linhagens avaliadas foram inferiores ao 'Hokuho', bem como às populações testadoras e aos híbridos experimentais (Tabela 1). Os valores obtidos, todas as médias superiores a 84\% (Tabela 1), foram elevados. Cardoso (2007) obteve médias variando de 63 a 89\%. Já Oviedo et al. (2008) obtiveram, em média, 64\% de frutos comerciais e Lima (2009), $61 \%$. Os valores obtidos são comuns em pepino caipira, conforme observado por Godoy et al. ('2008 e2009), com médias superiores a $81 \%$.

Para a característica MMFCOM foi observada a mesma tendência da característica \%FC. A população de Yoshinari $\left(\mathrm{T}_{\mathrm{Y}}\right)$, assim como os híbridos experimentais que a tinham como um de seus parentais $\left(\mathrm{H}_{. \mathrm{Y}}\right)$, com exceção de $\mathrm{H}_{6 \mathrm{Y}}$, foram estatisticamente semelhantes ao 'Hokuho' (testemunha) e às linhagens $\mathrm{L}_{1}, \mathrm{~L}_{2}$ e $\mathrm{L}_{3}$ (Tabela 1) e diferiram da população de Natsusuzumi $\left(\mathrm{T}_{\mathrm{N}}\right)$ e dos híbridos experimentais que o continham como um de seus genitores $\left(\mathrm{H}_{. \mathrm{N}}\right)$, exceto $\mathrm{H}_{3 \mathrm{~N}}, \mathrm{H}_{4 \mathrm{~N}}$ e $\mathrm{H}_{7 \mathrm{~N}}$. Ressalta-se que para esta característica, valores maiores indicam um fruto com maior diâmetro, o que é indesejável, pois, para pepino japonês, desejam-se frutos com diâmetro de até 3 $\mathrm{cm}$. Esta é uma característica do híbrido Natsusuzumi, conforme relatado por Cardoso \& Silva (2003).

Para Capacidade Geral de Combinação (CGC) do Grupo I (populações testadoras) foi observado significância $(\mathrm{p}<0,01)$ pelo teste $\mathrm{F}$, apenas para a característica MMFCOM. Já para o Grupo II (linhagens) não houve significância para a maioria das características, exceto para $\% \mathrm{FC}$, enquanto para $\mathrm{CEC}$ (combinações híbridas) não houve significância, pelo mesmo teste, para todas as características avaliadas.

De acordo com Sprague \& Tatum (1942), baixas estimativas de CGC indicam genitores em combinações que não diferem muito da média de todos os cruzamentos. Valores elevados de estimativas de CGC (com sinal positivo ou negativo) indicam um desvio em relação ao comportamento médio dos genitores, 
Tabela 1. Médias em pepino tipo japonês para características de produção de frutos em populações testadoras, linhagens, híbridos experimentais e no híbrido comercial Hokuho (averages in Japanese cucumber for fruit production characteristics of test populations, experimental lines and hybrids and commercial hybrid Hokuho). São Manuel, UNESP, 2004.

\begin{tabular}{|c|c|c|c|c|c|c|}
\hline & NFC/PL & NFT/PL & MC/PL (g) & MT/PL (g) & $\% \mathrm{FC}$ & MMFCOM (g) \\
\hline \multicolumn{7}{|c|}{ Populações testadoras } \\
\hline Yoshinari $\left(\mathrm{T}_{\mathrm{Y}}\right)$ & $12,4 \mathrm{a}$ & $12,9 \mathrm{a}$ & $1200 \mathrm{a}$ & $1512 \mathrm{a}$ & $95,22 \mathrm{a}$ & $96,82 \mathrm{~b}$ \\
\hline Natsusuzumi $\left(\mathrm{T}_{\mathrm{N}}\right)$ & $10,7 \mathrm{a}$ & $12,0 \mathrm{a}$ & $1129 \mathrm{a}$ & $1536 \mathrm{a}$ & $89,31 \mathrm{~b}$ & $105,72 \mathrm{a}$ \\
\hline \multicolumn{7}{|c|}{ Linhagens 'Hokuho' } \\
\hline $\mathrm{L}_{1}$ & $7,5 \mathrm{a}$ & $8,0 \mathrm{a}$ & $706 \mathrm{a}$ & $764 \mathrm{a}$ & $95,46 \mathrm{a}$ & $94,24 \mathrm{~b}$ \\
\hline $\mathrm{L}_{2}$ & $9,5 \mathrm{a}$ & $9,9 \mathrm{a}$ & $896 \mathrm{a}$ & $1121 \mathrm{a}$ & $97,36 \mathrm{a}$ & $95,17 \mathrm{~b}$ \\
\hline $\mathrm{L}_{3}$ & $7,6 \mathrm{a}$ & $8,1 \mathrm{a}$ & $704 \mathrm{a}$ & $890 \mathrm{a}$ & $91,91 \mathrm{~b}$ & $92,56 \mathrm{~b}$ \\
\hline $\mathrm{L}_{4}$ & $10,0 \mathrm{a}$ & $10,5 \mathrm{a}$ & $1033 \mathrm{a}$ & $1216 \mathrm{a}$ & $94,47 \mathrm{a}$ & $103,75 \mathrm{a}$ \\
\hline $\mathrm{L}_{5}$ & $7,7 \mathrm{a}$ & $8,2 \mathrm{a}$ & $877 \mathrm{a}$ & $1195 \mathrm{a}$ & $93,28 \mathrm{a}$ & $113,00 \mathrm{a}$ \\
\hline $\mathrm{L}_{6}$ & $9,1 \mathrm{a}$ & $10,0 \mathrm{a}$ & $983 \mathrm{a}$ & $1256 \mathrm{a}$ & $90,16 \mathrm{~b}$ & $107,09 \mathrm{a}$ \\
\hline $\mathrm{L}_{7}$ & $10,6 \mathrm{a}$ & $11,4 \mathrm{a}$ & $1122 \mathrm{a}$ & $1410 \mathrm{a}$ & $93,65 \mathrm{a}$ & $107,56 \mathrm{a}$ \\
\hline $\mathrm{L}_{8}$ & $8,3 \mathrm{a}$ & $9,8 \mathrm{a}$ & $912 \mathrm{a}$ & $1257 \mathrm{a}$ & $84,09 \mathrm{c}$ & $107,64 \mathrm{a}$ \\
\hline \multicolumn{7}{|c|}{ Híbridos experimentais } \\
\hline $\mathrm{H}_{1 \mathrm{Y}}$ & $11,4 \mathrm{a}$ & $11,7 \mathrm{a}$ & $1039 \mathrm{a}$ & $1207 \mathrm{a}$ & $97,66 \mathrm{a}$ & $90,19 \mathrm{~b}$ \\
\hline $\mathrm{H}_{2 \mathrm{Y}}$ & $8,8 \mathrm{a}$ & $9,2 \mathrm{a}$ & $854 \mathrm{a}$ & $1107 \mathrm{a}$ & $95,12 \mathrm{a}$ & $97,86 \mathrm{~b}$ \\
\hline $\mathrm{H}_{3 \mathrm{Y}}$ & $11,8 \mathrm{a}$ & $12,7 \mathrm{a}$ & 1149 a & $1530 \mathrm{a}$ & $91,79 \mathrm{~b}$ & $99,40 \mathrm{~b}$ \\
\hline $\mathrm{H}_{4 \mathrm{Y}}$ & $11,2 \mathrm{a}$ & $11,6 \mathrm{a}$ & $1069 \mathrm{a}$ & $1233 \mathrm{a}$ & $96,12 \mathrm{a}$ & $93,13 \mathrm{~b}$ \\
\hline $\mathrm{H}_{5 \mathrm{Y}}$ & $7,0 \mathrm{a}$ & $7,3 \mathrm{a}$ & $698 \mathrm{a}$ & $888 \mathrm{a}$ & $96,78 \mathrm{a}$ & $100,07 \mathrm{~b}$ \\
\hline $\mathrm{H}_{6 \mathrm{Y}}$ & $10,2 \mathrm{a}$ & $10,5 \mathrm{a}$ & $1131 \mathrm{a}$ & $1631 \mathrm{a}$ & $97,04 \mathrm{a}$ & $109,57 \mathrm{a}$ \\
\hline $\mathrm{H}_{7 \mathrm{Y}}$ & $11,1 \mathrm{a}$ & $11,6 \mathrm{a}$ & $1030 \mathrm{a}$ & $1210 \mathrm{a}$ & $95,73 \mathrm{a}$ & $91,67 \mathrm{~b}$ \\
\hline $\mathrm{H}_{8 \mathrm{Y}}$ & $12,2 \mathrm{a}$ & $12,8 \mathrm{a}$ & $1139 \mathrm{a}$ & $1288 \mathrm{a}$ & $94,98 \mathrm{a}$ & $96,98 \mathrm{~b}$ \\
\hline $\mathrm{H}_{1 \mathrm{~N}}$ & $9,9 \mathrm{a}$ & $10,2 \mathrm{a}$ & $1038 \mathrm{a}$ & $1235 \mathrm{a}$ & $95,78 \mathrm{a}$ & $106,14 \mathrm{a}$ \\
\hline $\mathrm{H}_{2 \mathrm{~N}}$ & $12,0 \mathrm{a}$ & $12,6 \mathrm{a}$ & $1230 \mathrm{a}$ & $1531 \mathrm{a}$ & $95,17 \mathrm{a}$ & $102,37 \mathrm{a}$ \\
\hline $\mathrm{H}_{3 \mathrm{~N}}$ & $9,4 \mathrm{a}$ & $10,0 \mathrm{a}$ & $921 \mathrm{a}$ & $1280 \mathrm{a}$ & $94,64 \mathrm{a}$ & $96,87 \mathrm{~b}$ \\
\hline $\mathrm{H}_{4 \mathrm{~N}}$ & $12,1 \mathrm{a}$ & $12,3 \mathrm{a}$ & $1135 \mathrm{a}$ & $1367 \mathrm{a}$ & $98,58 \mathrm{a}$ & $93,02 \mathrm{~b}$ \\
\hline $\mathrm{H}_{5 \mathrm{~N}}$ & $9,4 \mathrm{a}$ & $9,9 \mathrm{a}$ & $1008 \mathrm{a}$ & $1218 \mathrm{a}$ & $94,72 \mathrm{a}$ & $107,81 \mathrm{a}$ \\
\hline $\mathrm{H}_{6 \mathrm{~N}}$ & $9,7 \mathrm{a}$ & $10,5 \mathrm{a}$ & $1061 \mathrm{a}$ & $1435 \mathrm{a}$ & $91,96 \mathrm{~b}$ & $109,73 \mathrm{a}$ \\
\hline $\mathrm{H}_{7 \mathrm{~N}}$ & $10,0 \mathrm{a}$ & $10,4 \mathrm{a}$ & $1008 \mathrm{a}$ & $1299 \mathrm{a}$ & $95,72 \mathrm{a}$ & $100,41 \mathrm{~b}$ \\
\hline $\mathrm{H}_{8 \mathrm{~N}}$ & $9,6 \mathrm{a}$ & $10,4 \mathrm{a}$ & $995 \mathrm{a}$ & $1359 \mathrm{a}$ & $92,74 \mathrm{~b}$ & $103,41 \mathrm{a}$ \\
\hline Híbrido 'Hokuho' & $11,5 \mathrm{a}$ & $12,2 \mathrm{a}$ & $1151 \mathrm{a}$ & $1470 \mathrm{a}$ & $94,31 \mathrm{a}$ & $100,52 \mathrm{~b}$ \\
\hline $\mathrm{CV}(\%)$ & $26,6 \%$ & $26,1 \%$ & $28,0 \%$ & $25,2 \%$ & $4,4 \%$ & $7,3 \%$ \\
\hline
\end{tabular}

*médias seguidas da mesma letra, na coluna, não diferem entre si, pelo teste de Scott-Knott, a 5\% de probabilidade (*means followed by the same letter in the column did not differ from each other, Scott-Knott test $(\mathrm{p}<0,05)$; NFC/PL= número de frutos comerciais por planta; $\mathrm{NFT} / \mathrm{PL}=$ número total de frutos por planta; $\mathrm{MC} / \mathrm{PL}=$ massa de frutos comerciais por planta $(\mathrm{g}) ; \mathrm{MT} / \mathrm{PL}=$ massa total de frutos por planta $(\mathrm{g}) ; \% \mathrm{FC}=$ porcentagem de frutos comerciais; $\mathrm{MMFCOM}=$ massa média de frutos comerciais $(\mathrm{g})(\mathrm{NFC} / \mathrm{PL}=$ commercial number of fruits per plant; NFT/PL= total number of fruits per plant; $\mathrm{MC} / \mathrm{PL}=$ weight of commercial fruits per plant; $\mathrm{MT} / \mathrm{PL}=$ weight of total fruits per plant; $\% \mathrm{FC}=$ percentage of commercial fruits; MMFCOM= average weight of commercial fruits).

no sentido favorável ou desfavorável com predomínio de efeitos gênicos aditivos, ou seja, genes que podem ser transmitidos e se expressar em seus descendentes. Dessa forma, conforme os resultados observados, em média, a população de 'Yoshinari' apresenta maior quantidade de genes com efeitos aditivos favoráveis para aumento no
NFT/PL e NFC/PL em comparação com a população de 'Natsusuzumi'. Ressaltase que os valores não são desprezíveis. Por exemplo, para número de frutos comerciais por planta, o valor da CGC foi de 0,2 frutos por planta (Tabela 2). Para uma população de 20.000 plantas por hectare (espaçamento $1,0 \times 0,5$ ), a estimativa é obter 40.000 frutos por hectare, o que corresponde a cerca de $10 \%$ de acréscimo na produção.

Já para MC/PL e MT/PL a população de Natsusuzumi $\left(\mathrm{T}_{\mathrm{N}}\right)$ apresentou valor positivo da estimativa de CGC provavelmente por expressar a maior massa média de fruto comercial (Tabela 2). Esse fato revela que, em média, esta população apresenta maior quantidade 
Tabela 2. Estimativa dos efeitos de capacidade geral de combinação (CGC) de parentais, para características de produção de pepino pelo modelo de pais e $F_{1}$ 's (estimates of the effects of general combining ability (GCA) of parents, for production characteristics of cucumber by the parents and $F_{1}$ 's model). São Manuel, UNESP, 2004.

\begin{tabular}{lcrrrrc}
\hline & NFC/PL & NFT/PL & MC/PL & MT/PL & \%FC & MMFCOM \\
\hline Populações testadoras & \multicolumn{7}{c}{} & & & & \\
\hline Yoshinari $\left(\mathrm{T}_{\mathrm{Y}}\right)$ & 0,200 & 0,122 & $-6,031$ & $-28,271$ & 0,739 & $-2,320^{* *}$ \\
Natsusuzumi $\left(\mathrm{T}_{\mathrm{N}}\right)$ & $-0,200$ & $-0,122$ & 6,031 & 28,271 & $-0,739$ & 2,320 \\
\hline Linhagens 'Hokuho' & & & & & \\
\hline $\mathrm{L}_{1}$ & $-0,842$ & $-1,058$ & $-109,058$ & $-176,597$ & $1,450^{* *}$ & $-2,566$ \\
$\mathrm{~L}_{2}$ & 0,329 & 0,217 & 7,963 & 3,912 & 1,558 & $-2,606$ \\
$\mathrm{~L}_{3}$ & 0,271 & $-0,199$ & $-63,626$ & $-44,964$ & $-0,902$ & $-4,136$ \\
$\mathrm{~L}_{4}$ & 0,903 & 0,774 & 73,810 & 29,061 & 1,330 & $-1,593$ \\
$\mathrm{~L}_{5}$ & $-1,002$ & $-1,089$ & $-61,333$ & $-60,384$ & 0,400 & 4,612 \\
$\mathrm{~L}_{6}$ & 0,038 & 0,142 & 55,107 & 119,872 & $-1,057$ & 4,546 \\
$\mathrm{~L}_{7}$ & 0,754 & 0,789 & 75,535 & 78,591 & 0,515 & 0,166 \\
$\mathrm{~L}_{8}$ & 0,091 & 0,424 & 21,602 & 50,509 & $-3,293$ & 1,577 \\
\hline
\end{tabular}

** significativo pelo teste $\mathrm{F}$ em nível de $1 \% ; \mathrm{NFC} / \mathrm{PL}=$ número de frutos comerciais por planta; $\mathrm{NFT} / \mathrm{PL}=$ número total de frutos por planta; $\mathrm{MC} / \mathrm{PL}=$ massa de frutos comerciais por planta $(\mathrm{g}) ; \mathrm{MT} / \mathrm{PL}=$ massa total de frutos por planta $(\mathrm{g}) ; \% \mathrm{FC}=$ porcentagem de frutos comerciais; $\mathrm{MMFCOM}=$ massa média de frutos comerciais $(\mathrm{g})$ (** significant by $\mathrm{F}$ test $(1 \%) ;(\mathrm{NFC} / \mathrm{PL}=$ commercial number of fruits per plant; NFT/ $\mathrm{PL}=$ total number of fruits per plant; $\mathrm{MC} / \mathrm{PL}=$ weight of commercial fruits per plant; $\mathrm{MT} / \mathrm{PL}=$ weight of total fruits per plant; $\% \mathrm{FC}=$ percentage of commercial fruits; MMFCOM= average weight of commercial fruits).

Tabela 3. Estimativa da capacidade específica de combinação (CEC) dos híbridos experimentais de pepino, para características de produção pelo modelo de pais e $\mathrm{F}_{1}$ 's (estimates of the specific combining ability (SCA) of experimental hybrids of cucumber, of production characteristics of parents and $\mathrm{F}_{1}$ 's model) São Manuel, UNESP, 2004.

\begin{tabular}{lccrrrc}
\hline Híbridos & NFC/PL & NFT/PL & MC/PL & MT/PL & \%FC & MMFCOM \\
\hline $\mathbf{H}_{1 \mathbf{Y}}$ & 1,810 & 1,770 & 124,965 & 103,963 & 1,010 & $-5,606$ \\
$\mathbf{H}_{2 \mathbf{Y}}$ & $-2,051$ & $-2,004$ & $-177,116$ & $-176,897$ & $-1,638$ & 2,103 \\
$\mathbf{H}_{3 \mathbf{Y}}$ & 1,549 & 1,952 & 189,094 & 294,640 & $-2,508$ & 5,173 \\
$\mathbf{H}_{4 \mathbf{Y}}$ & $-0,184$ & $-0,191$ & $-27,643$ & $-75,805$ & $-0,410$ & $-0,640$ \\
$\mathbf{H}_{5 \mathbf{Y}}$ & $-2,469$ & $-2,638$ & $-263,449$ & $-331,220$ & 1,180 & $-2,905$ \\
$\mathbf{H}_{6 \mathbf{Y}}$ & $-0,279$ & $-0,579$ & 52,350 & 230,753 & 2,897 & 6,662 \\
$\mathbf{H}_{7 \mathbf{Y}}$ & $-0,146$ & $-0,166$ & $-68,958$ & $-148,465$ & 0,015 & $-6,858$ \\
$\mathbf{H}_{8 \mathbf{Y}}$ & 1,627 & 1,409 & 93,835 & $-42,104$ & 3,074 & $-2,960$ \\
$\mathbf{H}_{1 \mathbf{N}}$ & 0,671 & 0,555 & 112,233 & 75,261 & 0,608 & 5,703 \\
$\mathbf{H}_{2 \mathbf{N}}$ & 1,600 & 1,650 & 186,561 & 190,781 & $-0,110$ & 1,973 \\
$\mathbf{H}_{3 \mathbf{N}}$ & $-0,360$ & $-0,534$ & $-50,849$ & $-12,002$ & 1,819 & $-1,997$ \\
$\mathbf{H}_{4 \mathbf{N}}$ & 1,106 & 0,803 & 25,895 & 1,883 & 3,528 & $-8,391$ \\
$\mathbf{H}_{5 \mathrm{~N}}$ & 0,311 & 0,296 & 34,328 & $-58,462$ & 0,598 & 0,194 \\
$\mathbf{H}_{6 \mathrm{~N}}$ & $-0,419$ & $-0,375$ & $-29,692$ & $-21,769$ & $-0,705$ & 2,181 \\
$\mathbf{H}_{7 \mathbf{N}}$ & $-0,825$ & $-1,082$ & $-103,250$ & $-115,957$ & 1,483 & $-2,759$ \\
$\mathbf{H}_{8 \mathbf{N}}$ & $-0,532$ & $-0,777$ & $-61,677$ & $-28,005$ & 2,311 & $-1,171$ \\
\hline
\end{tabular}

$\mathrm{NFC} / \mathrm{PL}=$ número de frutos comerciais por planta; $\mathrm{NFT} / \mathrm{PL}=$ número total de frutos por planta; $\mathrm{MC} / \mathrm{PL}=$ massa de frutos comerciais por planta $(\mathrm{g}) ; \mathrm{MT} / \mathrm{PL}=$ massa total de frutos por planta $(\mathrm{g}) ; \% \mathrm{FC}=$ porcentagem de frutos comerciais; $\mathrm{MMFCOM}=$ massa médio de frutos comerciais $(\mathrm{g})(\mathrm{NFC} / \mathrm{PL}=$ number of commercial fruits per plant; $\mathrm{NFT} / \mathrm{PL}=$ total number of fruits; $\mathrm{MC} / \mathrm{PL}=$ weight of commercial fruits per plant; $\mathrm{MT} / \mathrm{PL}=$ weight of total fruits; $\% \mathrm{FC}=$ percentage of commercial fruits; MMFCOM= average weight of commercial fruits). de genes com efeitos aditivos que favorecem o aumento desta característica, o que nem sempre é desejável, pelos motivos já discutidos anteriormente.

As linhagens $\mathrm{L}_{1} \mathrm{~L}_{2}$ e $\mathrm{L}_{4}$ apresentaram os maiores valores positivos de estimativa da CGC para \% FC (Tabela $2)$, significando que podem proporcionar, em média, uma melhoria na qualidade dos frutos nos híbridos, enquanto a linhagem $\mathrm{L}_{8}$ apresentou o pior resultado. De forma geral, as linhagens $\mathrm{L}_{4}$ e $\mathrm{L}_{7}$ apresentaram os valores mais favoráveis para CGC, para a maioria das características avaliadas, significando que estas linhagens podem proporcionar ganhos superiores nos cruzamentos em que participam devido ao acúmulo de genes com efeito aditivo favoráveis para aumentar a produção de frutos por planta. Por outro lado, as linhagens $\mathrm{L}_{1}$, $\mathrm{L}_{3}$ e $\mathrm{L}_{5}$, expressaram, para a maioria das características, valores negativos de CGC.

Também não houve diferença estatística significativa para as estimativas da CEC, para as características avaliadas. Porém, no geral, os híbridos que continham a linhagem $\mathrm{L}_{1}$ como genitora $\left(\mathrm{H}_{1 \mathrm{Y}}\right.$ $\mathrm{e}_{1 \mathrm{~N}}$ ) foram os que apresentaram maiores valores para $\mathrm{CEC}$, para a maioria das 
Tabela 4. Heterose em porcentagem dos híbridos em relação a média dos seus parentais, para características de produção de pepino (heterosis in percentage of hybrids on the average of their parents, for production characteristics of cucumber). São Manuel, UNESP, 2004.

\begin{tabular}{lcrrrcc}
\hline Híbridos & NFT/PL & NFC/PL & MT/PL & MC/PL & MMFCOM & \%FC \\
\hline $\mathbf{H}_{1 \mathbf{Y}}$ & 23,7 & 26,5 & 10,3 & 18,9 & $-7,0$ & 2,4 \\
$\mathbf{H}_{2 \mathbf{Y}}$ & $-19,3$ & $-20,1$ & $-15,9$ & $-18,5$ & 1,9 & $-1,2$ \\
$\mathbf{H}_{3 \mathbf{Y}}$ & 20,8 & 18,2 & 27,4 & 21,6 & 5,0 & $-1,9$ \\
$\mathbf{H}_{4 \mathbf{Y}}$ & $-1,3$ & 0,1 & $-9,6$ & $-4,2$ & $-4,1$ & 1,3 \\
$\mathbf{H}_{5 \mathbf{Y}}$ & $-31,5$ & $-30,3$ & $-34,4$ & $-32,7$ & $-4,6$ & 2,7 \\
$\mathbf{H}_{6 \mathbf{Y}}$ & $-8,1$ & $-4,6$ & 17,8 & 3,6 & 7,5 & 4,7 \\
$\mathbf{H}_{7 \mathbf{Y}}$ & $-4,8$ & $-3,7$ & $-17,2$ & $-11,3$ & $-10,3$ & 1,4 \\
$\mathbf{H}_{8 \mathbf{Y}}$ & 12,8 & 18,0 & $-6,9$ & 7,8 & $-5,1$ & 5,9 \\
$\mathbf{H}_{1 \mathbf{N}}$ & 14,2 & 20,4 & 11,6 & 23,8 & 4,6 & 3,7 \\
$\mathbf{H}_{2 \mathbf{N}}$ & 15,5 & 18,5 & 15,2 & 21,5 & 1,9 & 2,0 \\
$\mathbf{H}_{3 \mathbf{N}}$ & $-0,4$ & 3,5 & 5,5 & 1,3 & $-2,3$ & 4,4 \\
$\mathbf{H}_{4 \mathbf{N}}$ & 9,7 & 16,6 & $-0,6$ & 5,0 & $-11,2$ & 7,3 \\
$\mathbf{H}_{5 \mathbf{N}}$ & $-1,5$ & 1,7 & $-10,8$ & 0,5 & $-1,4$ & 3,8 \\
$\mathbf{H}_{6 \mathbf{N}}$ & $-4,4$ & $-2,0$ & 2,8 & 0,4 & 3,1 & 2,5 \\
$\mathbf{H}_{7 \mathbf{N}}$ & $-10,8$ & $-6,4$ & $-11,8$ & $-10,5$ & $-5,8$ & 4,6 \\
$\mathbf{H}_{8 \mathbf{N}}$ & $-4,5$ & 1,4 & $-2,7$ & $-2,5$ & $-3,1$ & 7,0 \\
\hline
\end{tabular}

$\mathrm{NFC} / \mathrm{PL}=$ número de frutos comerciais por planta; NFT/PL= número de frutos totais por planta; $\mathrm{MC} / \mathrm{PL}=$ massa de frutos comerciais por planta $(\mathrm{g}) ; \mathrm{MT} / \mathrm{PL}=$ massa de frutos totais por planta $(\mathrm{g}) ; \% \mathrm{FC}=$ porcentagem de frutos comerciais; $\mathrm{MMFCOM}=$ massa média de frutos comerciais $(\mathrm{g})(\mathrm{NFC} / \mathrm{PL}=$ commercial number of fruits per plant; $\mathrm{NFT} / \mathrm{PL}=$ total number of fruits; $\mathrm{MC} / \mathrm{PL}=$ weight of commercial fruits per plant; $\mathrm{MT} / \mathrm{PL}=$ weight of total fruits; $\% \mathrm{FC}=$ percentage of commercial fruits; MMFCOM= average weight of commercial fruits).

características avaliadas (Tabela 3). Isso revela uma boa complementação gênica entre esses materiais testados, já que a CEC é, em grande parte, dependente de locos com efeito de dominância e/ ou epistasia. Segundo Miranda Filho \& Gorgulho (2001), a CEC é interpretada como um efeito na expressão do híbrido que é adicional aos efeitos da CGC, podendo melhorar ou piorar a expressão do híbrido em relação ao efeito esperado com base somente nas CGC.

Para a maioria das características avaliadas, exceto para massa média de frutos comerciais e porcentagem de frutos comerciais, foi observada heterose positiva para os híbridos $\mathrm{H}_{1 \mathrm{Y}}$ e $\mathrm{H}_{3 \mathrm{Y}}$, variando de 2,4 a $27,4 \%$ (Tabela 4). Tendência semelhante para essas características foram observadas por Pinto (1978), Giordano et al. (1982), Filgueira et al. (1986), Cui et al. (1992), Li et al. (1995), Godoy et al. (2008) e Lima (2009). Por sua vez, o híbrido $\mathrm{H}_{5 \mathrm{Y}}$ revelou os menores valores de heterose, variando de $-4,6$ a $-4,4 \%$.
Em geral, a população de Yoshinari $\left(\mathrm{T}_{\mathrm{Y}}\right)$ foi a que apresentou, em média, a melhor capacidade de se combinar com as linhagens de Hokuho, ou seja, há um alto potencial de se extrair linhagens de Yoshinari para cruzamentos com linhagens de Hokuho, a fim de se obter híbridos tão bons ou melhores que o Hokuho, isto é, com elevado potencial produtivo.

Da mesma forma, as linhagens $\mathrm{L}_{7}$ e $\mathrm{L}_{4}$ foram as que revelaram os maiores valores positivos de CGC para a maioria das características avaliadas, significando que essas linhagens, nos cruzamentos em que participam, tendem a proporcionar maior acúmulo de genes com efeito aditivo favoráveis, podendo ser consideradas linhagens interessantes em futuras combinações com linhagens obtidas a partir do híbrido Yoshinari.

\section{REFERÊNCIAS}

CARDOSO AII. 2006. Dialelo entre linhagens de uma população de pepino tipo 'Caipira'. Horticultura Brasileira 24: 259-263.

CARDOSO AII. 2007. Avaliação de linhagens e híbridos experimentais de pepino do grupo varietal japonês sob ambiente protegido. Bragantia 66: 473-479.

CARDOSO AII; SILVA. N. 2003. Avaliação de híbridos de pepino tipo japonês sob ambiente protegido em duas épocas de cultivo. Horticultura Brasileira 21: 170-175.

DAVIS RL. 1927. Report of the plant breeder. Puerto Rico: Agr. Exp. Sta. p.14-15.

DELANEY DE; LOWER RL. 1987. Generation means analysis of plant characters in crosses between two determinate cucumber lines and Cucumis sativus var. hardwickii. The Journal of the American Society for Horticultural Science 112: 707-711.

FILGUEIRA FAR. 2003. Novo manual de olericultura: agrotecnologia moderna na produção e comercialização de hortaliças. Viçosa: UFV. 402p.

FILGUEIRA FAR; GIORDANO, LB; FERREIRA, PE; VECHIA, PTD. 1986. Avaliação de híbridos $\mathrm{F}_{1}$ de pepino do tipo caipira. Horticultura Brasileira 4: 17-20.

GERALDI IO; MIRANDA FILHO JB. 1988. Adapted models for the analysis of combining ability of varieties in partial diallel crosses. Revista Brasileira de Genética 11: 419-30.

GHADERI A; LOWER RL. 1978. Heterosis and phenotypic stability of $F_{1}$ hybrids in controlled environment. The Journal of the American Society for Horticultural Science 103: 275-278.

GIORDANO LB; FERREIRA PE; LOPES JF. 1982. Análise dialélica em pepino para mesa, visando o estudo de características relativas à produção. Horticultura Brasileira 3: 16-20.

GODOY AR; CASTRO MM; CARDOSO AII. 2009. Desempenho produtivo, partenocarpia e expressão sexual de linhagens de pepino caipira em ambiente protegido. Horticultura Brasileira 27: 150-154.

GODOY AR; HIGUTI ARO; CARDOSO AII. 2008. Produção e heterose em cruzamentos entre linhagens de pepino do grupo caipira. Bragantia 67: 817-825.

HUTCHINS AE. 1938 Some examples of heterosis in cucumber Cucumis sativus L. Proceedings of the American Society for Horticultural Science 36: 660-664.

IEA - Instituto de Economia Agrícola e Coordenadoria de Assistência Técnica Integral. 2009, Disponível em www.iea.sp.gov.br/out/ banco/menu.php, acessado em 03/08/2009.

JENKINS MT; BRUNSON AM. 1932. Methods of testing inbred lines of maize in crossbred combinations. American Society of Agronomic Journal 24: 523-530.

KOCH PS. 1995. Análise genética de um cruzamento dialélico em abobrinha (Cucurbita pepo L.). Piracicaba: USP-ESALQ. 79p. (Tese mestrado).

LI JW; LI JW; WEI ZD. 1995. Genetic analysis for major agronomic characters in cucumber (Cucumis sativus L.). Acta Horticulturae 402: 388-391.

LIMAATS. 2009 Análise dialélica entre linhagens 
de pepino do tipo japonês. Botucatu: FCAUNESP. 48p. (Tese Mestrado).

LOWER RL; NIENHUIS J; MILLER CH. 1982. Gene action and heterosis for yield and vegetative characteristics in a cross between a gynoecious pickling cucumber inbred and a Cucumis sativus var. hardwickii line. The Journal of the American Society for Horticultural Science 107: 75-78.

MALUF WR. 2001. Heterose e emprego de híbridos $\mathrm{F}_{1}$ em hortaliças. In: NASS LL; VALOIS ACC; MELO IS; VALADARES MC. (eds). Recursos genéticos e melhoramento: plantas. Rondonópolis: Fundação MT. p. 327-356.

MIRANDA FILHO JB; GORGULHO EP. 2001. Cruzamentos com testadores e dialelos. In: NASS LL; VALOIS ACC; MELO IS; VALADARES MC. (eds). Recursos genéticos e melhoramento - plantas. Rondonópolis: Fundação MT, p.650-671.

OVIEDO VRS; GODOY AR; CARDOSO AII. 2008. Inbreeding depression evaluation of japanese cucumber population. Scientia Agricola 65: 553-556.

PINTO CABP. 1978. Hibridos simples e triplos de pepino (Cucumis sativus L.). Piracicaba: USP-ESALQ. 57p. (Tese mestrado).

ROBINSON RW; DECKER-WALTERS DS. 1999.

Cucurbits. Cambridge: CAB International. 226p.

SPRAGUE GF; TATUM LA. 1942. General vs. specific combining ability in single crosses of corn. Journal of the American Society of Agronomy 34: 923-932.

TRANI PE; PASSOS FA; AZEVEDO AA; TAVARES M. 1997. Recomendações de adubação e calagem para o Estado de São Paulo. Campinas: IAC. 258p. (Boletim técnico, 100). 